JPE 10-2-13

\title{
An Improved Control Strategy Using a PI-Resonant Controller for an Unbalanced Stand-Alone Doubly-Fed Induction Generator
}

\author{
Van-Tung Phan*, Hong-Hee Lee ${ }^{\dagger}$, and Tae-Won Chun* \\ $\dagger *$ School of Electrical Engineering, University of Ulsan, Ulsan, Korea
}

\begin{abstract}
The main cause of degradation in an unbalanced stand-alone doubly-fed induction generator (DFIG) system is negative sequence components that exist in the generated stator voltages. To eliminate these components, a hybrid current controller composed of a proportional-integral controller and a resonant regulator is developed in this paper. The proposed controller is applied to the rotor-side converter of a DFIG system for the purpose of compensating the negative stator voltage sequences. The proposed current controller is implemented in a single positive rotating reference frame and therefore the controller can directly regulate both the positive and negative sequence components without the need for sequential decomposition of the measured rotor currents. In terms of compensation capability and accuracy, simulations and experimental results demonstrated the excellent performance of the proposed control method when compared to conventional vector control schemes.
\end{abstract}

Key Words: Doubly-fed induction generator (DFIG), Resonant controller, Unbalanced stand-alone system, Wind energy

\section{INTRODUCTION}

In recent years, many variable-speed wind turbines for both grid-connected and stand-alone wind power generation systems have been developed based on doubly-fed induction generators (DFIG) [1]-[4] which offers several advantages when compared to other generator systems. These advantages include ease of speed control, decoupled active and reactive power capability, and an inverter rated at approximately 20$30 \%$ of the total system power.

The majority of DFIG studies have focused on symmetrical network voltage or balanced loads. However, in practical use, unexpected conditions such as network disturbances, unbalanced grid voltages and unbalanced loads exist. For such DFIG systems, if a voltage imbalance condition is not taken into account by the control system, the stator voltage could be highly unbalanced. Such a scenario creates heat on the stator windings and reduces the lifetime of the generator.

The analysis and operation of grid-connected DFIG systems under an unbalanced grid voltage have been widely investigated in the literature [5]-[8]. In order to eliminate the torque pulsation due to the presence of a negative sequence current, one control method based on a rotor-side converter (RSC) was outlined in [5]. In that study, a torque pulsation at twice the supply frequency was reduced by generating the required compensating rotor currents. In [6], a detailed investigation of

\footnotetext{
Manuscript received Oct. 9, 2009; revised Feb. 3, 2010

$\dagger$ Corresponding Author: hhlee@mail.ulsan.ac.kr

Tel: +82-52-259-2187, Fax: +82-52-259-2186, University of Ulsan

* School of Electrical Engineering, University of Ulsan
}

the impact of an unbalanced stator voltage on the pulsations of DFIG stator and rotor currents, torque, and stator active and reactive power was presented. The proposed control considerations were also performed on an RSC controller in which there was inadequate capability for reducing both torque and active power oscillations. To overcome this problem, the coordinated control of both the rotor-side and grid-side converters within a DFIG was proposed in [7], [8]. Based on this improvement, the dynamic performance of DFIG systems can be significantly improved.

Besides taking into account a grid-connected DFIG system, the control and operation of a stand-alone or isolated DFIGbased wind energy system (shown in Fig. 1) was presented in [2]. For stand-alone DFIG applications, the system itself must regulate both the output voltage and frequency in a stable manner. One proposed compensation method was briefly introduced in [9], where a stand-alone DFIG supplying an unbalanced load was considered. However, in [9], there was no detailed explanation of the design for the current controller or the unbalanced voltage compensation method. In another paper by the same authors [10], the modeling and control of a DFIG based on a grid-side converter (GSC) for unbalanced operation was investigated for both grid-connected and stand-alone applications. In [9] and [10], dual synchronous rotating reference frames, called positive and negative rotating reference frames, were used for decomposing the positive and negative sequence components of current values. The main drawback of this approach was a considerable time delay due to the complicated calculations such as multiple frame 


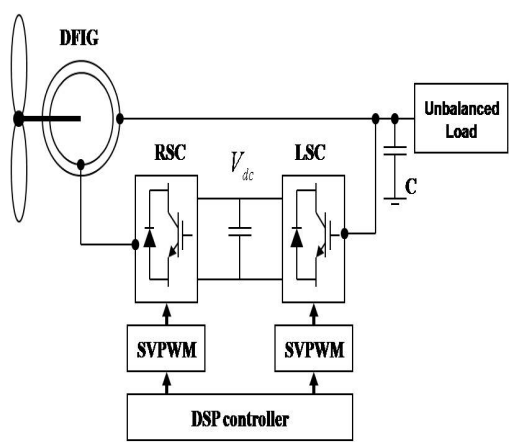

Fig. 1. The typical configuration of a stand-alone DFIG-based wind generator.

transformations and decompositions, which led to errors with respect to the original signals. Furthermore, such a control scheme for a current controller requires a wide bandwidth in order to make it suitable for controlling both of the separate sequences.

Among the previously proposed current control strategies in the literature, proportional-integral (PI) controllers have been widely used in current controllers to compensate for errors because of their simplicity and effectiveness. However, PI controllers have certain limitations and drawbacks when used to accurately regulate $\mathrm{AC}$ reference currents due to their limited bandwidth. To remove these shortcomings, a resonant controller was introduced in [11] and [12] as an improved solution in term of the AC reference tracking performance in grid-connected converters. Due to the infinite gain at a selected resonant frequency, this controller is capable of completely eliminating the steady-state control error at that frequency.

In this paper, a new control strategy using a hybrid current controller (HCC) for the stand-alone DFIG system, developed by the authors in [13], was proposed so as to enhance the compensation capability and to improve the dynamic performance. The proposed HCC, which is a combination of a PI controller and a resonant regulator, was constructed in a single positive rotating reference frame instead of the dual frames used in [6]-[8]. As a result, the proposed current controller can directly regulate both the positive and negative sequence components without the need for the sequential decomposition of the measured rotor currents, as in [9], [10]. Consequently, the complexity of the calculations for the proposed control algorithm was simplified and therefore the control performance was significantly improved. The proposed control method was investigated solely with respect to the RSC of a DFIG control system in order to compensate for the generated stator voltage unbalances caused by unbalanced loads. In addition, the simulations and experimental setup were implemented under different unbalanced load conditions in order to verify the feasibility and effectiveness of the compensation method with the proposed control approach.

\section{Control Of A Rsc With Unbalanced LoAds}

The control and operation of balanced stand-alone DFIG systems are described in [2]. In this section, an analysis was performed on a vector-controlled DFIG-based variablespeed wind energy system that supplied electrical energy to

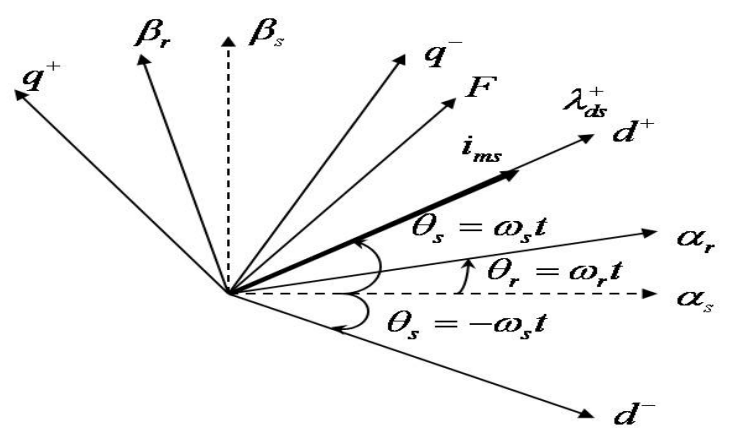

Fig. 2. The vector diagram representing both positive and negative synchronous rotating reference frames.

an unbalanced stand-alone load or isolated grid. Under this load operating condition, the stator voltage, current, torque, flux, and power included both positive and negative sequence components that caused fluctuations at twice the synchronous frequency. The following subsection will describe the control strategy used by a RSC to compensate for the unbalanced stator voltages. A method of calculating the reference rotor currents for the proposed current controller is also outlined.

\section{A. Dynamic modeling of a RSC}

The main purpose of a RSC is to control the stator voltage magnitude and frequency. In stand-alone operations, a DFIGbased wind energy system has to supply a constant voltage and frequency to the stator terminals irrespective of variations in rotor speed. The control system for a DFIG under an unbalanced load was developed based on a stator flux-oriented vector control strategy. Fig. 2 shows a vector diagram that represents the relationship between a stationary frame $\alpha_{s} \beta_{s}$, a rotor frame $\alpha_{r}, \beta_{r}$ rotating with an angular speed $\omega_{r}$, a positive frame $d_{q}{ }^{+}$rotating with an angular speed $\omega_{r}$, and a negative frame $d_{q}{ }^{-}$rotating with an angular speed $-\omega_{s}$. The superscripts + and - represent positive and negative synchronous reference frames, respectively. The vector $F$ denotes the values of the voltage, current, or flux in the stator flux-oriented reference frame.

Under an unbalanced load, the most convenient method for analyzing a DFIG model is to use a positive reference frame rotating at a speed of $\omega_{s}$ and a negative reference frame rotating at a speed of $-\omega_{s}$. According to Fig. 2, the relationship of a vector $F$ between different frames is illustrated as follows:

$$
\begin{aligned}
& F_{d q}^{+}=F_{\alpha_{s} \beta_{s}} e^{-j \omega_{s} t}=F_{d q}^{-} e^{-j 2 \omega_{s} t} \\
& F_{d q}^{-}=F_{\alpha_{s} \beta_{s}} e^{j \omega_{s} t}=F_{d q}^{+} e^{j 2 \omega_{s} t} .
\end{aligned}
$$

In addition, the stator and rotor current, voltage, and flux vectors $F$ can be expressed with their respective positive and negative sequences as:

$$
F_{d q}^{+}=F_{d q+}^{+}+F_{d q-}^{+}=F_{d q+}^{+}+F_{d q-}^{-} e^{-j 2 \omega_{s} t}
$$

where the subscripts + and - represent the positive and the negative sequence components, respectively.

An inspection of (2) reveals that the vector $F$ in a positive rotating reference frame is the sum of both the DC and 


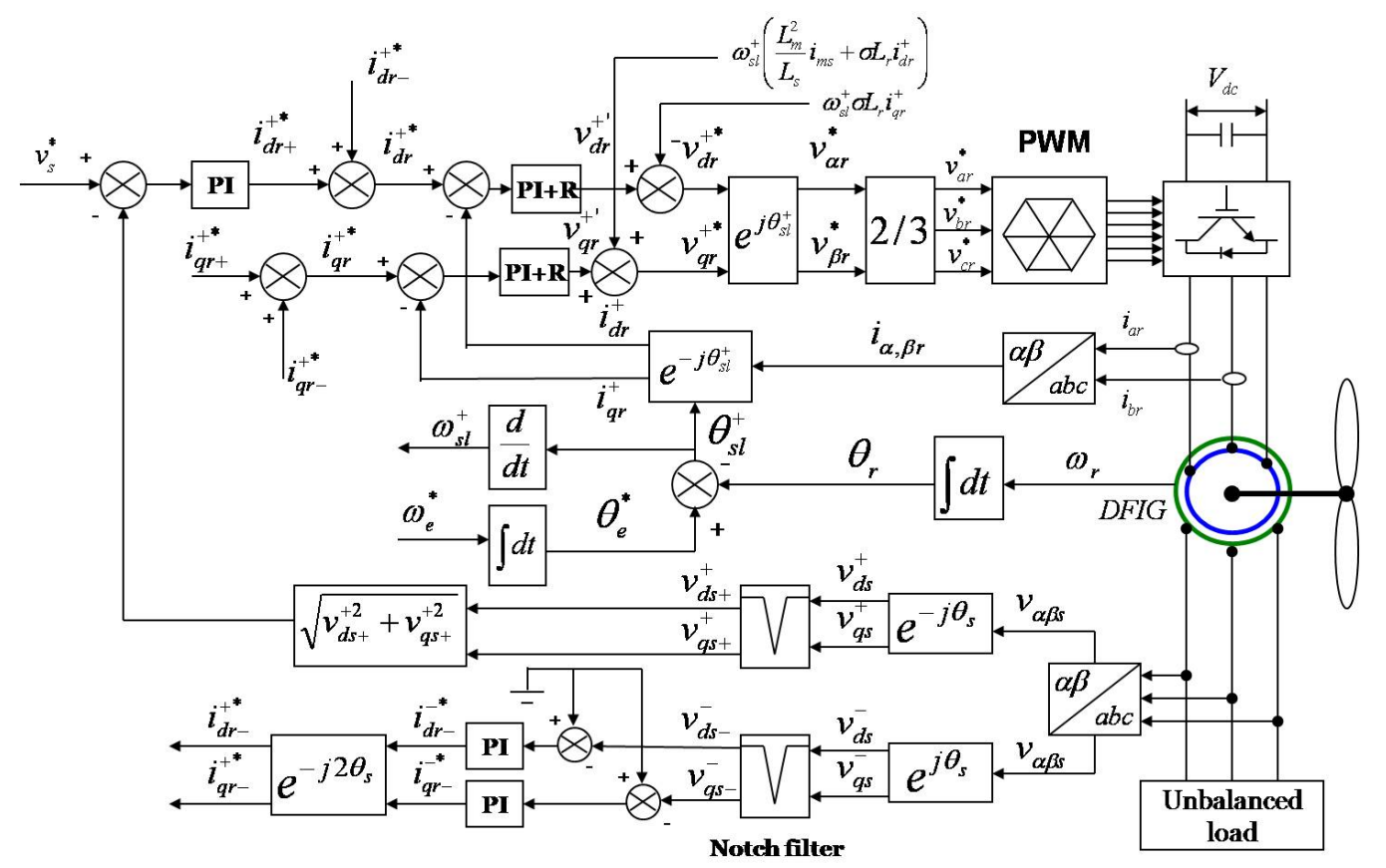

Fig. 3. The proposed current control scheme for the RSC of a DFIG using PI-R controller.

$\mathrm{AC}$ components at twice the synchronous frequency. The AC component is the main cause of the unbalance and fluctuation conditions in the machine. Taking into consideration the control variables in the RSC, the rotor voltage in the RSC can be expressed as:

$$
v_{r}^{+}=R_{r} i_{r}^{+}+\sigma L_{r} \frac{d i_{r}^{+}}{d t}+\frac{L_{m}}{L_{s}} \frac{d \lambda_{s}^{+}}{d t}+j \omega_{s l}^{+}\left(\frac{L_{m}}{L_{s}} \lambda_{s}^{+}+\sigma L_{r} i_{r}^{+}\right)
$$

where $R_{r}$ is the rotor resistance, $L_{s}$ is the stator inductance, $L_{r}$ is the rotor inductance, $L_{m}$ is the mutual inductance, $\lambda_{s}^{+}$ denotes the stator flux in the $d q^{+}$reference frame, $\sigma$ represents the total leakage factor, and $\omega_{s l}^{+}=\omega_{s}-\omega_{r}$ is the slip speed in the positive reference frame.

A block diagram of a stand-alone DFIG with the proposed stator voltage compensation method is presented in Fig. 3 . The magnitude of the stator voltage is controlled directly with a given specific command value $v_{s}^{*}$ by adding an external voltage control loop. The specific magnitude of the stator voltage is obtained from the positive sequence components of the measured voltage signals, given as:

$$
v_{s}=\sqrt{v_{d s+}^{+2}+v_{q s+}^{+2}} .
$$

In stand-alone DFIG applications, the magnetizing current $i_{m s}$ is supplied directly from the rotor side converter by a daxis rotor current. The equations used to express the dynamic response and the steady-state of the magnetizing current are:

$$
\begin{aligned}
\tau_{s} \frac{d i_{m s}}{d t}+i_{m s} & =i_{d r+}^{+}+\frac{\left(1+\sigma_{s}\right)}{R_{s}} v_{d s+}^{+} \\
i_{m s} & =i_{d r+}^{+}+\left(1+\sigma_{s}\right) i_{d s+}^{+}
\end{aligned}
$$

where $\tau_{s}=L_{s} / R_{s}$ and $\sigma_{s}=L_{s} / L_{m}-1$ are the electrical time constant of the stator circuit and the stator leakage factor, respectively.
As evident in (5), the induced stator voltage, which is controlled by the stator magnetizing current, can be directly regulated from the direct rotor current $i_{d r+}^{+}$in the positive reference frame. The output of the stator voltage PI controller is the d-axis positive sequence component of the rotor reference current.

When generating the reference value for the q-axis rotor current, it is important to force the stator flux to align on the $\mathrm{d}$-axis positive rotating reference frame. As a result, the q-axis stator flux becomes zero and the q-axis rotor reference current is determined as:

$$
i_{q r+}^{+^{*}}=-\frac{L_{s}}{L_{m}} i_{q s+}^{+} .
$$

Under unbalanced load operations, the stator voltage and current values in the positive rotating reference frame include both DC and AC values at double-frequency due to the presence of negative sequence components. In order to balance the generated stator voltage, the negative sequence components must be eliminated by applying a control algorithm in the RSC. The following sub-section explains this operation in more detail.

\section{B. Generation of reference $d-q$ rotor currents}

A HCC is used to precisely track the reference rotor currents, which are determined based on the elimination of the negative sequence components of the stator voltage. The reference currents contain both DC and AC components. The DC components have been explained in (5) and (6). The AC components are derived from the negative sequence components, which are added to the reference rotor currents to compensate for the unbalanced stator voltages. As shown in Fig. 3, these values are the outputs of the two PI controllers. 


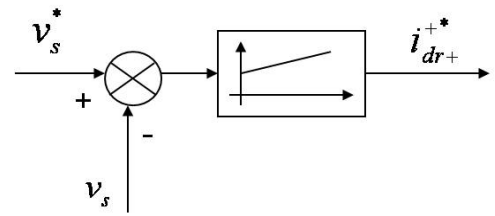

Fig. 4. The outer control loop of the stator voltage.

These controllers are used to drive the negative sequence components of the stator voltage to zero in the negative rotating reference frame. A notch filter is used to extract the values of $v_{d s-}^{-}$and $v_{q s-}^{-}$from the components in the negative rotating reference frame.

The negative reference rotor currents, $i_{d r-}^{-*}$ and $i_{q r-}^{-*}$, are obtained from the negative reference frame and are used to compensate for the generated stator output voltage unbalance. In order to use these components in a current controller in the positive synchronous reference frame, they are transformed into positive coordinates $d q^{+}$using the angle $2 \theta_{s}$, given by:

$$
\begin{aligned}
& i_{d r-}^{+^{*}}=i_{d r-}^{-^{*}} e^{-j 2 \theta_{s}} \\
& i_{q r-}^{+^{*}}=i_{q r-}^{-^{*}} e^{-j 2 \theta_{s}} .
\end{aligned}
$$

Therefore, the $d q^{+}$reference rotor currents for the proposed current controllers are the sum of the positive and negative sequence references, given by:

$$
\begin{aligned}
& i_{d r}^{+^{*}}=i_{d r+}^{+^{*}}+i_{d r-}^{+^{*}} \\
& i_{q r}^{+^{*}}=i_{q r+}^{+^{*}}+i_{q r-}^{+^{*}}
\end{aligned}
$$

where $i_{d r+}^{+^{*}}$ is the output of the stator voltage magnitude PI controller, as shown in Fig. 4, and $i_{q r+}^{+^{*}}$ is determined in (6).

\section{Voltage unbalance factor}

The effect of stator voltage unbalance under unbalanced load conditions can be severe on generators and power electronic converters, causing more losses and heating effects. To assess such adverse effects, the "true" voltage unbalance factor (UF) for three-phase sinusoidal voltage waveforms is presented in [15]. According to this, the UF is defined as:

$$
U F(\%)=\frac{V_{-}}{V_{+}} \times 100 \%
$$

where $V_{+}$and $V_{-}$are the modulus of the root mean square (RMS) of the positive and negative sequence components, respectively. These components are calculated based only on the RMS values of the line voltages (10), which are possible to measure.

$$
\begin{aligned}
V_{+} & =\sqrt{\frac{A_{m}^{2}+\frac{4 A_{s}^{2}}{\sqrt{3}}}{2}, \quad V_{-}=\sqrt{\frac{A_{m}^{2}-\frac{4 A_{s}^{2}}{\sqrt{3}}}{2}}} \\
A_{m}^{2} & =\frac{V_{A B}^{2}+V_{B C}^{2}+V_{C A}^{2}}{3} \\
A_{s}^{2} & =\sqrt{p\left(p-V_{A B}\right)\left(p-V_{B C}\right)\left(p-V_{C A}\right)} \\
p & =\frac{V_{A B}+V_{B C}+V_{C A}}{3} .
\end{aligned}
$$

Using this method, we consider the stator voltage unbalance due to the different types of unbalanced loads at the stator terminals, i.e., one phase and three phase unbalances.

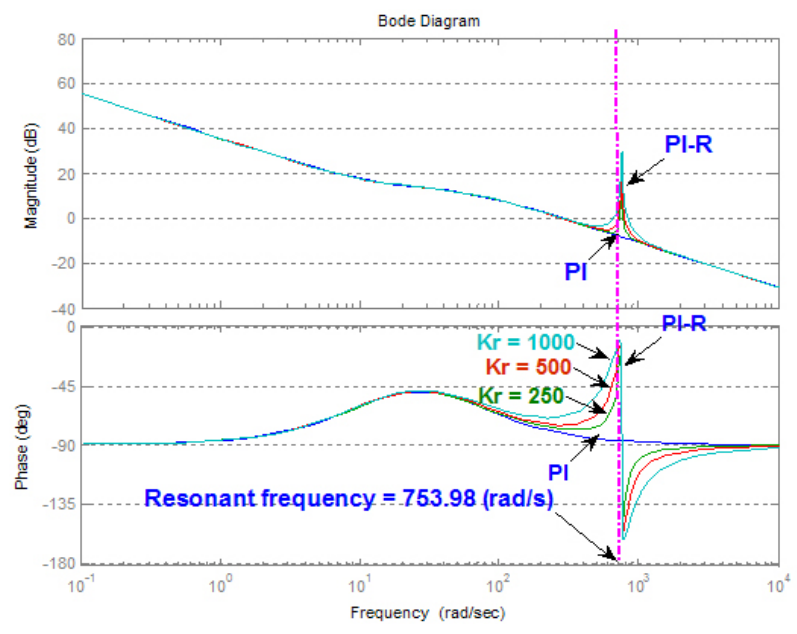

Fig. 5. Bode diagrams of open loop PI and PI-R controllers.

\section{The Proposed HCC Using A PI-R Regulator}

\section{A. Advantageous characteristics of the HCC}

The use of a notch filter for the purpose of decomposing the positive and the negative sequence components of the control variable causes more time delays and increases the bandwidth of the controller. As a result, the proposed current controller was implemented in the positive rotating reference frame only. The decomposition process of the measured signals can be practically implemented by digital notch or low-pass filters. Under an unbalanced load condition, the control system for a DFIG must be precisely controlled during both the transient process and in the steady-state. Therefore, the use of a decomposing control signals in the current controllers significantly degrades system stability and efficiency.

To improve the accuracy of the control system, a HCC applied to the RSC of a DFIG was employed in this paper. One of the most important features of a resonant controller is that it is capable of sufficiently tracking the $\mathrm{AC}$ reference current and therefore, can eliminate the steady-state control variable errors at the chosen (resonant) frequencies. The s-domain open-loop transfer function of a PI-R current controller is defined as follows:

$$
G_{o}(s)=K_{p}+\frac{K_{i}}{s}+K_{R} \frac{s}{s^{2}+\omega_{0}^{2}}
$$

where $K_{p}$ is the proportional gain, $K_{i}$ is the integral gain, $K_{R}$ denotes the resonant gain, and $\omega_{0}=2 \omega_{s}$ is the resonant frequency at which the synchronous frequency is $f=60 \mathrm{~Hz}$.

Fig. 5 describes the magnitude and phase characteristics of the open loop transfer functions for both the PI controller and the PI-R with respect to different values of the resonant gain $K_{r}$. The large gain produced at the resonant frequency ensures that the steady-state errors in the rotor currents can be completely eliminated. Furthermore, the selection of resonant gain values determines the cross-over frequency and the dynamic response of the control system. As illustrated in Fig. 5, a low $K_{R}$ gives a very narrow bandwidth, whereas a high $K_{R}$ leads to larger bandwidth. Shown in Fig. 6 are the bode-diagrams of the closed-loop transfer functions of the PI$\mathrm{R}$ current controller when compared with a conventional PI 


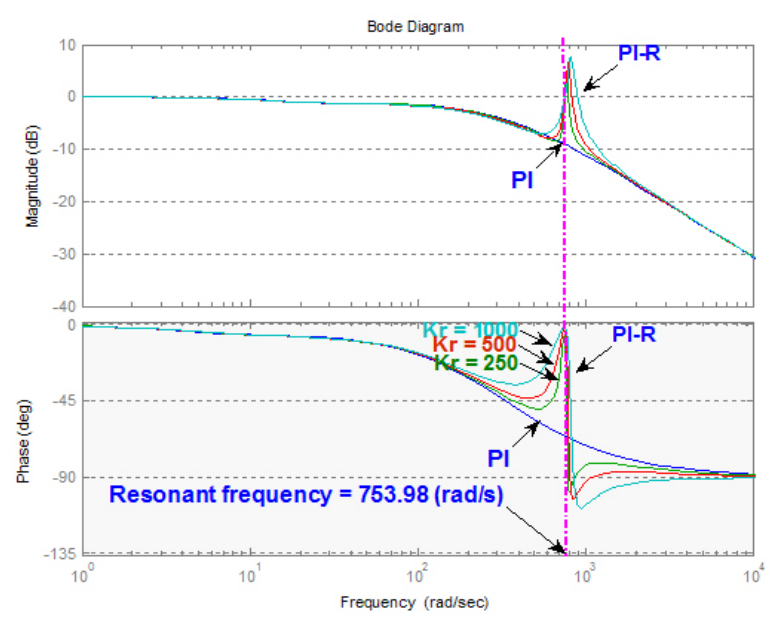

Fig. 6. Bode diagrams of closed-loop PI and PI-R controllers.

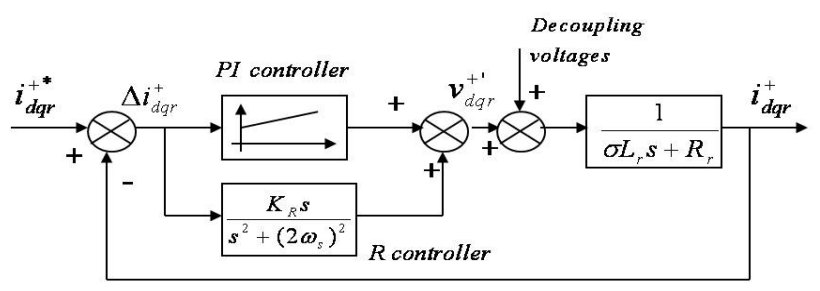

Fig. 7. Block diagram of the proposed PI-R current controller.

controller. The gains used in both bode-diagrams are designed based on the Naslin polynomial technique, which is introduced in [14]. The specific gain values used in the experimental process are $K_{p}=3, K_{i}=120$, and $K_{R}=1000$. The design process of these gains is more clearly explained in the following sub-section. As shown in Fig. 6, the proposed controller with a resonant controller provides accurate control with the characteristic of unity gain $(0 \mathrm{~dB})$ and minimum phase error at the resonant frequency. In this paper, the HCC using a PI-R was implemented in a single positive reference frame without a decomposition process for the measured current signals. Taking full advantage of this type of controller, the $\mathrm{AC}$ component existing in the control variable was effectively controlled using the $\mathrm{R}$ regulator.

\section{B. Current controller design}

A closed-loop current control scheme is described in Fig. 7. In order to determine if the proposed controller could achieve zero steady-state control errors, an analytical investigation regarding its frequency response when operating in a closedloop system was employed. The closed-loop transfer function of the control scheme is given by:

$$
G_{c}(s)=\frac{i_{d q r}^{+}(s)}{i_{d q r}^{+*}(s)}=\frac{G_{o}(s)}{\left(\sigma L_{r} s+R_{r}\right)+G_{o}(s)} .
$$

Substituting $s=j 2 \omega_{s}$ into (12), we can see that the frequency response of the closed-loop transfer function at twice the synchronous frequency is equal to 1 , as computed in (13). This means that good performance can be obtained from the control system with unity gains and zero phases.

$$
\left.G_{c}(s)\right|_{s=j 2 \omega_{s}}=\frac{G_{0}\left(j 2 \omega_{s}\right)}{\left(\sigma L_{r} j 2 \omega_{s}+R_{r}\right)+G_{0}\left(j 2 \omega_{s}\right)}=1 .
$$

It is concluded that the proposed controller can precisely track the current control variables with zero steady-state errors at a specific resonant frequency $2 \omega_{s}$, regardless of the effects of the generator parameters $R_{r}$ and $\sigma L_{r}$.

As mentioned above, the current controller design was implemented based on the Naslin polynomial technique and it was used to determine the controller gains. The characteristic polynomial of the closed-loop transfer function in (12) can be calculated as:

$$
\begin{aligned}
D(s)= & \left(\sigma L_{r} s+R_{r}\right) s\left(s^{2}+\omega_{0}^{2}\right)+K_{p} s\left(s^{2}+\omega_{0}^{2}\right) \\
& +K_{i}\left(s^{2}+\omega_{0}^{2}\right)+K_{R} s^{2} .
\end{aligned}
$$

The parameters of the controller are computed based on the fourth-order Naslin polynomial as follows:

$$
N(s)=a_{0}\left(1+\frac{s}{\omega_{n}}+\frac{s^{2}}{\alpha \omega_{n}^{2}}+\frac{s^{3}}{\alpha^{3} \omega_{n}^{3}}+\frac{s^{4}}{\alpha^{6} \omega_{n}^{4}}\right)
$$

where $\alpha$ is the characteristic ratio and $\omega_{n}$ is the Naslin frequency.

From these quantities, matching the coefficients for (14) and (15) gives the controller gains to be used in the proposed current controller.

$$
\begin{aligned}
\omega_{0}^{2} & =\alpha^{3} \omega_{n}^{2} \\
K_{p} & =\sigma L_{r} \alpha^{3} \omega_{n}-R_{r} \\
K_{i} & =\sigma L_{r} \alpha^{3} \omega_{n}^{2} \\
K_{R} & =\sigma L_{r} \omega_{n}^{2}\left(\alpha^{5}-2 \alpha^{3}\right) .
\end{aligned}
$$

The characteristic ratio of the Naslin polynomial is generally chosen to be $\alpha=2$. Thus, the appropriate gains of the proposed current controller are obtained from (16).

The discrete transfer functions of both the PI and R controllers for digital implementation are presented below:

$$
\begin{aligned}
P I(z) & =\frac{\left(K_{p}+K_{i} T_{s}\right) z-K_{p}}{(z-1)} \\
R(z) & =\frac{K_{R} T_{s}\left[z^{2}-\cos \left(2 \omega_{s} T_{s}\right) z\right]}{z^{2}-2 \cos \left(2 \omega_{s} T_{s}\right) z+1}
\end{aligned}
$$

where $z$ is the shift operator and $T_{s}$ is the sampling period.

\section{Rotor voltage generation for the RSC}

The reference rotor currents possess AC components. The errors between the reference and measured rotor currents are the inputs of the PI-R controller. The required control voltages that are to be applied to the converters are the outputs of the proposed current controller. The output rotor voltages are determined by:

$$
\begin{aligned}
v_{d q r}^{++^{\prime}} & =G_{c}(s)\left(i_{d q r}^{+^{*}}-i_{d q r}^{+}\right) \\
& =\left(K_{p}+\frac{K_{i}}{s}+K_{R} \frac{s}{s^{2}+\left(2 \omega_{s}\right)^{2}}\right)\left(i_{d q r}^{+^{*}}-i_{d q r}^{+}\right) .
\end{aligned}
$$

In order to improve the decoupling between the $\mathrm{d}$ and q components of the rotor currents, the decoupling voltage 


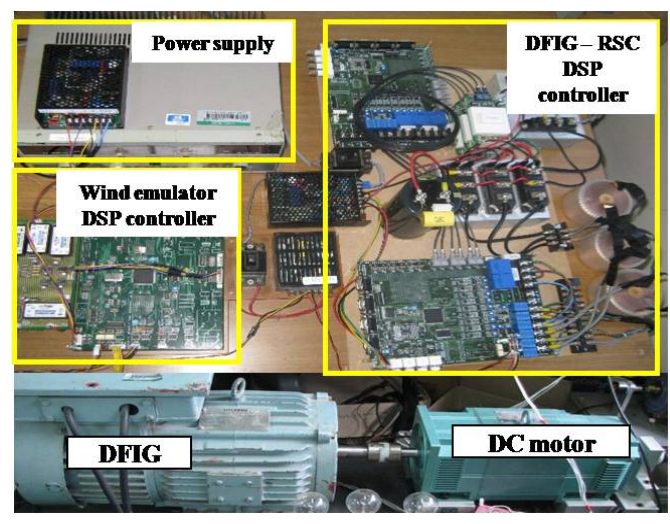

Fig. 8. The experimental platform for the DFIG system.

components $-\omega_{s l}^{+} \sigma L_{r} i_{q r}^{+}$and $\omega_{s l}^{+} \sigma L_{r} i_{d r}^{+}$are added to (18), as shown in (19). Furthermore, it is necessary to include the feed-forward compensation $\omega_{s l}^{+} i_{m s} L_{m}^{2} / L_{s}$ in the rotor voltage control variables. This parameter compensates for disturbances caused by the rotor back-electromagnetic force (EMF).

$$
\begin{aligned}
& v_{d r}^{+^{*}}=v_{d r}^{\prime}-\omega_{s l}^{+} \sigma L_{r} i_{q r}^{+} \\
& v_{q r}^{+^{*}}=v_{q r}^{\prime}+\omega_{s l}^{+} \sigma L_{r} i_{d r}^{+}+\omega_{s l}^{+} \frac{L_{m}^{2}}{L_{s}} i_{m s} .
\end{aligned}
$$

Because the modulation index of a doubly-fed induction machine must be performed in a rotor-oriented frame, the outputs of the rotor current controller have to be transformed from a stator-flux orientation to a rotor reference frame. This is performed using a positive angle slip $\theta_{s l}^{+}$in a positive reference frame.

\section{Simulations And ExPERImental Results}

Simulations and experiments were carried out in order to verify the dynamic behavior of the proposed control method. The simulation was performed using PSIM software. The experimental platform was setup in a laboratory to implement the DFIG system and to verify the proposed control scheme. An overview of the experimental system is shown in Fig. 8. The system consists of a $2.2 \mathrm{~kW}$ DFIG, rotated by a DC motor that is emulated as a prime mover with torque and speed control. The RSC is fed by an insulated-gate-bipolartransistor (IGBT)-based PWM inverter in which the switching frequency is $10 \mathrm{kHz}$. The system was developed with a high performance DSP (TMS320F28335 by Texas Instruments). To test the dynamic performance of the proposed controller, the generator was operated under different loads. The line to the neutral stator voltage was controlled at about $145 \mathrm{~V}$. The two types of unbalanced loads for the tests were $30 \Omega, 50 \Omega, 50 \Omega$ (type I) with a $U F=11 \%$ and $30 \Omega, 40 \Omega, 50 \Omega$ (type II) with a $U F=24 \%$. Each load subset was connected to one of the three-phase stator terminals $\mathrm{A}, \mathrm{B}$, or C.

To verify the feasibility and effectiveness of the proposed current control technique, a series of experimental tests outlined in Figs. 9-13 was performed with a type I load. Fig. 9 shows the simulation results pertaining to the dynamic performance of the generated stator voltages, currents, and their negative sequence components when unbalanced loads are connected to the stator terminals. Operating under this

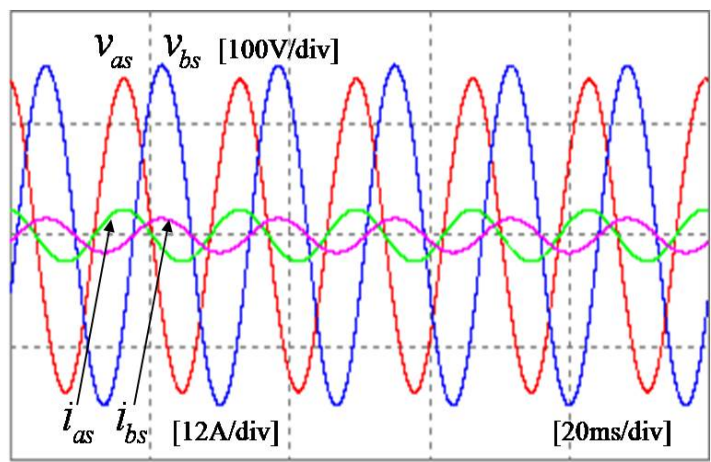

(a)

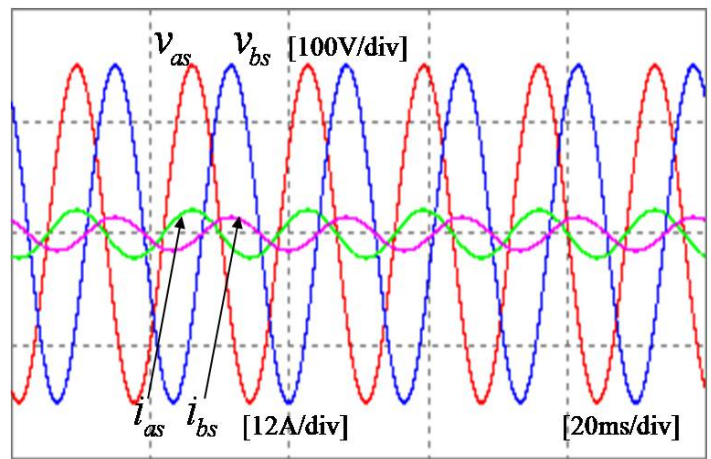

(b)

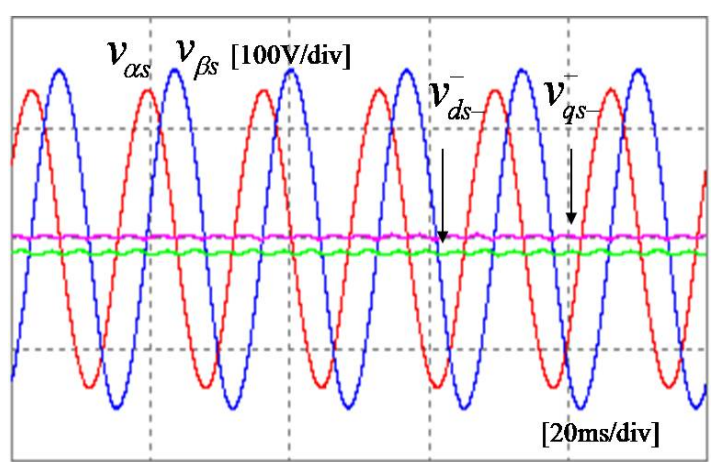

(c)

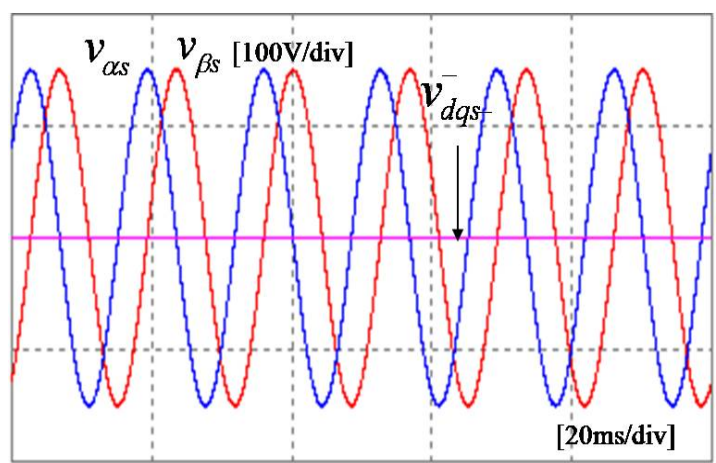

(d)

Fig. 9. Simulated results for stator voltage and current (a)-(b) before compensation and (c)-(d) after compensation.

condition, the stator voltage became unbalanced because its negative sequence components needed to be eliminated, as indicated in Fig. 9(a) and 9(b). Figs 9(c) and 9(d) show the stator voltages and current waveforms after applying the 


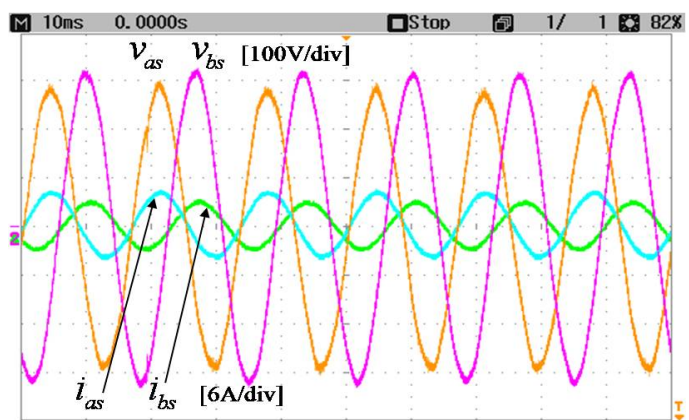

(a)

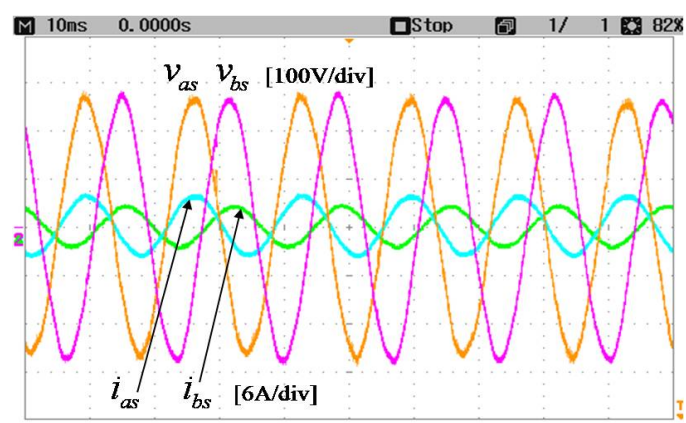

(b)

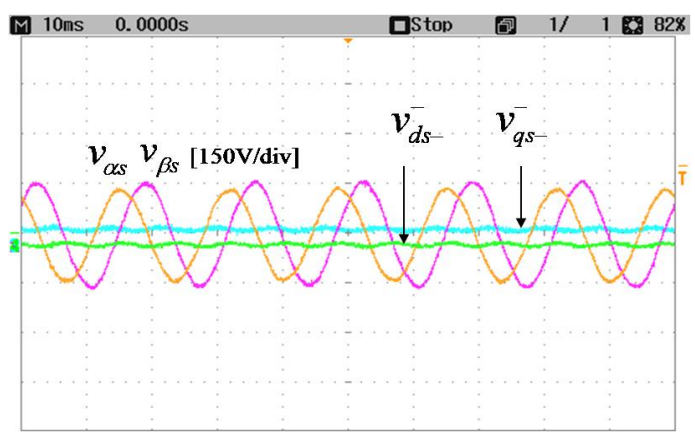

(c)

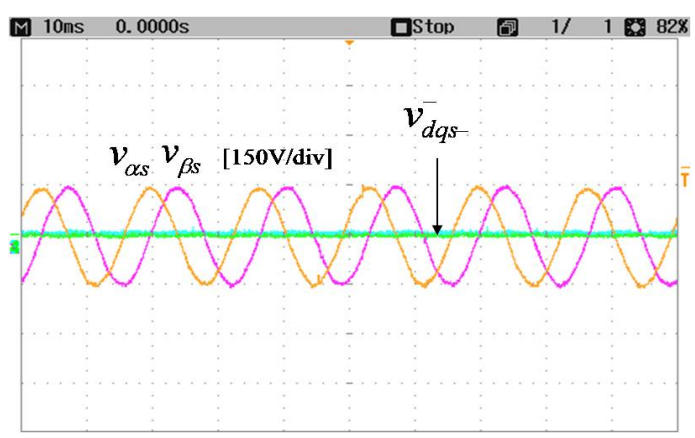

(d)

Fig. 10. Experimental results for stator voltage and current (a)-(b) before compensation and (c)-(d) after compensation.

proposed HCC to the RSC. As evident in the steady-state, the negative sequence components of the stator voltage $v_{d q s-}^{-}$ are completely eliminated. Thus, the generated stator voltages become fully balanced and exhibit excellent performance. The experimental results obtained with the same conditions used in the simulation above are shown in Fig. 10. Very good agreement is observed between the simulated and experimental results.

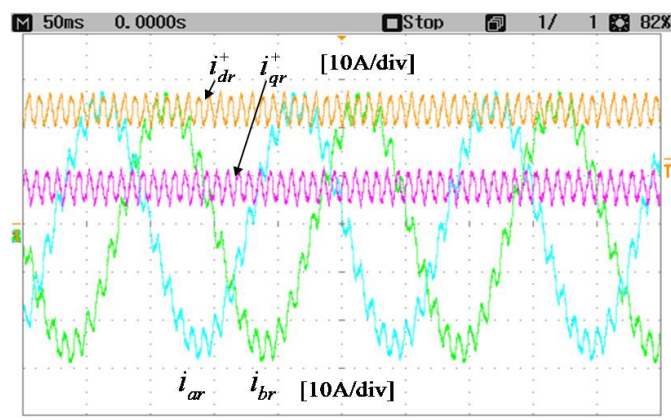

Fig. 11. Experimental results for steady state rotor current of the proposed control method.

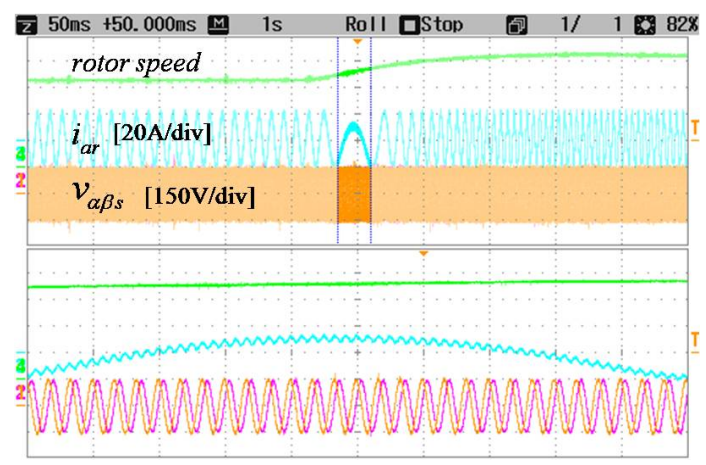

Fig. 12. Dynamic response of stator voltage and rotor current through synchronous speed.

It is clear that the stator voltages become balanced after applying the proposed compensation method to the RSC for the DFIG system. The steady state performance of the rotor currents is shown in Fig. 11. The proposed compensation method is based on generating appropriate reference rotor currents composed of both positive sequence and injected negative sequence components, as described in (8). Therefore, these rotor currents consist of both DC and AC components with a double synchronous frequency that gives adequate rotor current control for the elimination of an unbalanced condition in the stator voltages. The three-phase rotor currents are distorted as a result of the injected negative sequence component.

The dynamic response of the DFIG under operating conditions through the synchronous speed is presented in Fig. 12. The rotor speed is changed from sub-synchronous to supersynchronous. Sufficient performance of the rotor currents and stator voltages are observed. As seen in Fig. 12, during speed variation through the synchronous speed, the stator voltages are effectively controlled and compensated with good performance in terms of the compensation ability in the unbalanced condition.

It is important to compare the control performances and accuracies of a conventional PI controller and the proposed PI-R controller. For this test, both the PI controller and the proposed current controller PI-R were applied to the RSC. From Fig. 13, it can be confirmed that the proposed control strategy gives more adequate and accurate control when compared to the traditional PI controller due to its limited control bandwidth. In Figs. 13(a) and 13(b), the measured waveforms of the stator voltage, rotor current, and d-axis rotor current error are shown. 


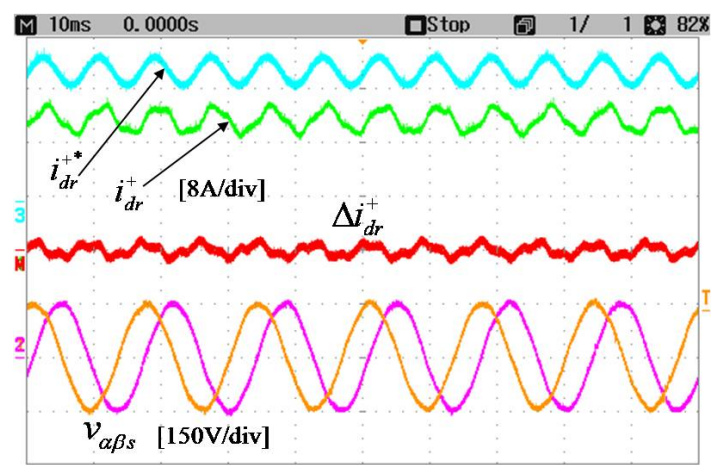

(a) PI controller

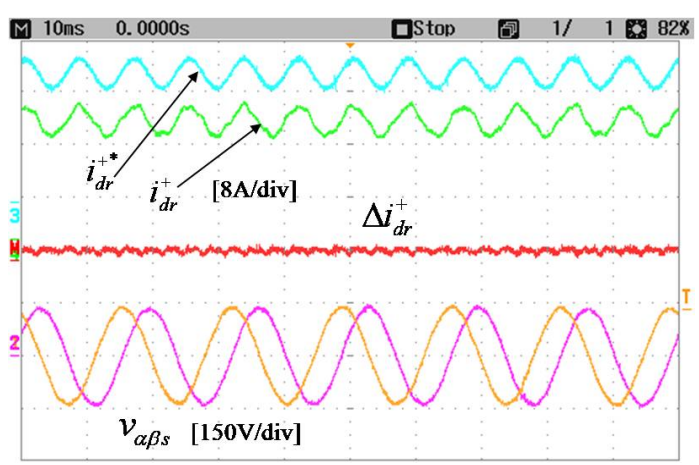

(b) PI-R controller

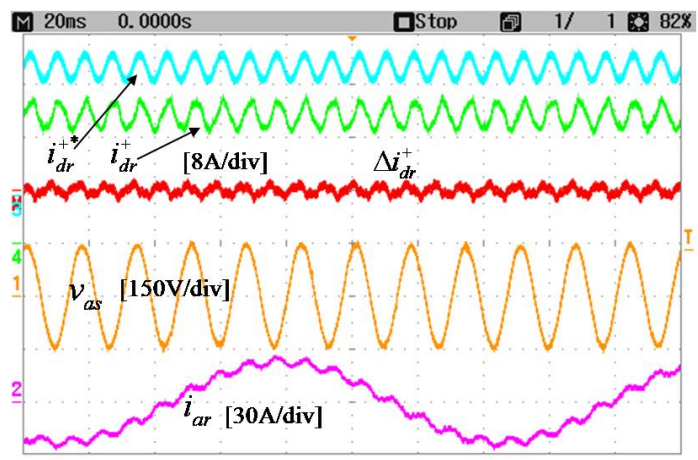

(c) PI controller

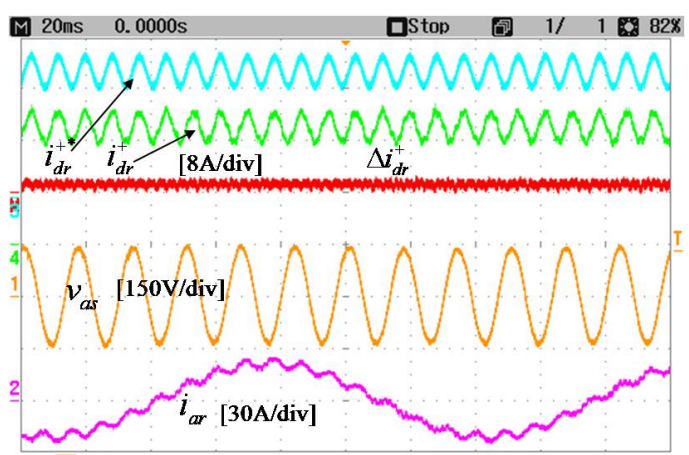

(d) PI-R controller

Fig. 13. Comparison of control performance between PI and PI-R controller in the RSC.

Likewise, Figs. 13(c) and (d) show the obtained balanced stator voltage with the dynamic behavior of the proposed current controller applied to the RSC. Taking into account the error of the d-component current value, Fig. 13 indicates that the proposed PI-R controller exhibits adequate and precise control.

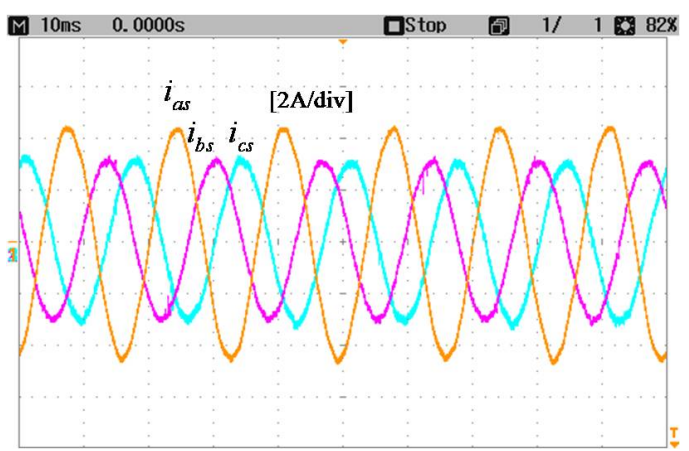

(a) Stator currents with type I load

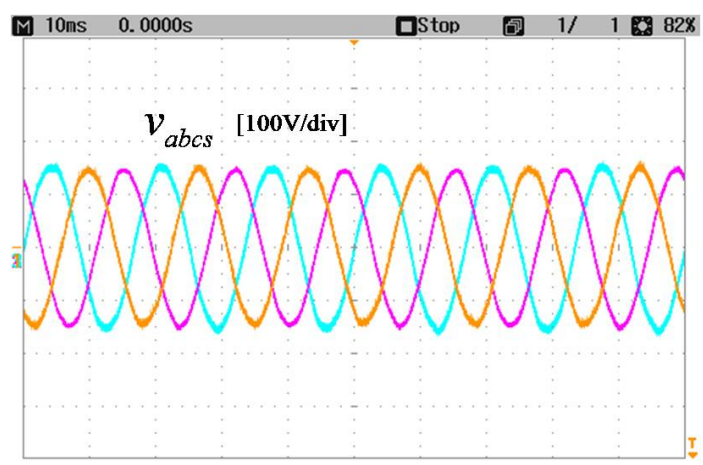

(b) Stator voltages with type I load

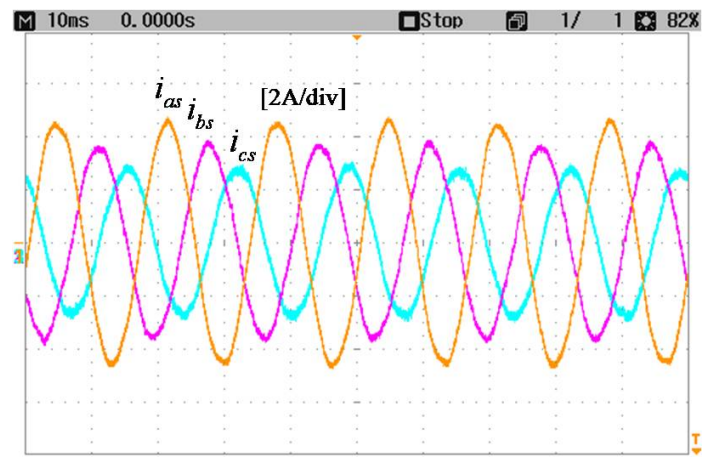

(c) Stator currents with type II load

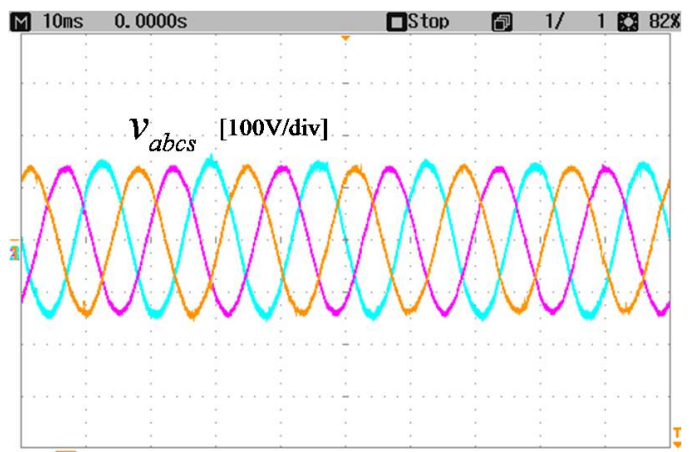

(d) Stator voltages with type II load

Fig. 14. Performances of the HCC at different load conditions.

In contrast, the conventional PI controller resulted in imprecise control due to insufficient control bandwidth.

In order to test the efficiency of the current controller, both type I and II load conditions were implemented. As shown previously, all of the tests were implemented with respect to a type I unbalanced load. To verify the accuracy and robustness 
of the proposed current controller, the type II load condition was used in this test. Operating under this condition, the load in phase B was increased, and the system became threephase unbalanced. This implies that the effect of this load condition on the stator voltage imbalance is much greater than in the previous case. The proposed controller, however, is able to effectively satisfy the compensation requirement. Fig. 14 shows the waveforms of the stator current and stator voltage with the compensation method. In both cases, the three-phase output stator voltages of the DFIG are welltracked despite the influence of the different unbalanced load conditions connected to the generator.

\section{Conclusions}

In this paper, an improved control strategy based on a HCC was presented to enhance the dynamic performance of a stand-alone DFIG system under unbalanced load operating conditions. The complexity of the calculations in the control algorithm was simplified by removing the decomposition process for the measured rotor currents, and as a result, the control performance was significantly improved.

The operation of the proposed controller was shown to be quite satisfactory with various unbalanced loads. In addition, it is clear from the results that compensation for the unbalanced stator voltage of the DFIG is achieved with the proposed controller. An experimental comparison between PI and HCC controllers in regards to accuracy and robustness was also given to verify the performance of the proposed control strategy. This strategy is applicable to a variable-speed unbalanced stand-alone or a grid-connected DFIG-based wind system. The effectiveness of the proposed method has been proven through theoretical analysis, simulations, and experiments.

\section{ACKNOWLEDGMENT}

This work was supported by a Research Fund from the University of Ulsan.

\section{REFERENCES}

[1] R. Pena, J. C. Clare and G. M. Asher, "Doubly fed induction generator using back-to-back PWM converters and its application to variable-speed wind energy generation", IEE Proc. Electric Power Applciations, Vol. 143, No. 3, pp. 231-241, May 1996.

[2] R. Pena, J. C. Clare and G. M. Asher, "A doubly fed induction generator using back-to-back PWM converters supplying an isolated load from a variable speed wind turbine", IEE Proc. Electric Power Applciations, Vol. 143, No. 5, pp. 380-387, Sep. 1996.

[3] S. Muller, M. Deicke, R.W, and De Doncker, "Doubly fed induction generator system for wind turbines", IEEE Industry Application Magazine, Vol. 8, No. 3, pp. 26-33, Feb. 2002.

[4] Arantxa Tapia, Gerardo Tapia, J. Xabier Ostolaza, and Jose Ramon Saenz, "Modeling and control of a wind turbine driven doubly fed induction generator", IEEE Transactions on Energy Conversion, Vol. 18, No. 2, pp. 194-204, Jun. 2003.

[5] Ted K. A. Brekken, Ned Mohan, "Control of a doubly fed induction wind generator under unbalanced grid voltage conditions", IEEE Transactions on Energy Conversion, Vol. 22, No. 1 pp. 129-135, Mar. 2007.
[6] Lie Xu, Yi Wang, "Dynamic modeling and control of DFIG-based wind turbine under unbalanced network conditions", IEEE Transactions on Power Systems, Vol. 22, No. 1 pp. 314-323, Feb. 2007.

[7] Lie Xu, "Coordinated control of DFIG's rotor and grid side converters during network unbalance", IEEE Transactions on Power Electronics, Vol. 23, No. 3 pp. 1041-1049, May 2008.

[8] Lie Xu, "Enhanced control and operation of DFIG-based wind farms during network unbalance", IEEE Transactions on Energy Conversion, Vol. 23, No. 4 pp. 1073-1081, Dec. 2008.

[9] R. Pena, et al, "Control system for unbalanced operation of standalone doubly fed induction generator", IEEE Transactions on Energy Conversion, Vol. 22, No. 2 pp. 544-545, Jun. 2007.

[10] R. Pena, et al, "Control strategy for a doubly fed induction generator feeding an unbalanced grid or stand-alone load", Electric Power Systems Research, Jul. 2008.

[11] R. Teodorescu, et al, "Proportional-resonant controllers and filters for grid-connected voltage source converters", Electric Power Application, IEE Proceedings, Vol. 153, No. 5 pp. 750-762, Sep. 2006.

[12] Marco Liserre, Remus Teodorescu, and Frede Blaabjerg, "Multiple harmonics control for three-phase grid converter systems with the use of PI-RES current controller in a rotating frame", IEEE Transactions on Power Elecronics, Vol. 21, No. 3 pp. 836-841, May 2006.

[13] Van-Tung Phan, Sung-Hyo Kwak, Hong-Hee Lee, "An improved control method for DFIG-based wind system supplying unbalanced stand-alone loads", Proceedings of the IEEE ISIE, pp. 1081-1086, Jul. 2009.

[14] Marian P. Kazmierkowski, R. Krishnan, F. Blaabjerg, "Control in Power Electronics: selected problems", Academic Press, 2002.

[15] J. A. L. Ghijselen and A. P. M. van de Bossche, "Exact voltage unbalance assessment without phase measurements", IEEE Transactions on Power System, Vol. 20, No. 1, pp. 519-520, Feb. 2005.

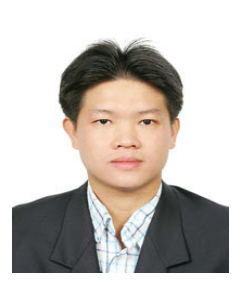

Van-Tung Phan was born in Binh Dinh province, Vietnam, in 1982. He received his B.S. in Electrical Engineering from the University of Technology, Ho Chi Minh city, Vietnam, in 2005. Since Sep 2005, he has been with the Department of Electrical Engineering at the University of Ulsan, Korea, where he has been a graduate student working towards his M.S. and Ph.D. His research interests include power electronics, the application of DFIG and PMSG, and advanced control techniques applied to wind power system.

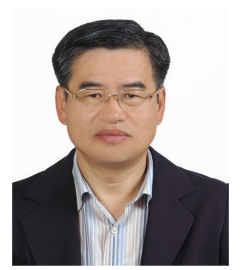

Hong-Hee Lee (M'96) is a professor in the School of Electrical Engineering, University of Ulsan, Ulsan, Korea. He is also the Director of the Network-based Research Center (NARC). He received his B.S., M.S., and Ph.D. in Electrical Engineering from Seoul National University, Seoul, Korea, in 1980, 1982, and 1990, respectively. His current research interests include power electronics, network-based motor control, and control networks. He is a member of the Institute of Electrical and Electronics Engineers (IEEE), the Korean Institute of Power Electronics (KIPE), the Korean Institute of Electrical Engineers (KIEE), and the Institute of Control, Automation, and Systems Engineers (ICASE).

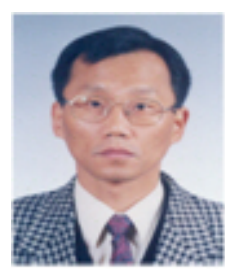

Tae-Won Chun was born in Korea in 1959. He received his B.S. in Electrical Engineering from Pusan National University in 1981, and his M.S. and Ph.D. in Electrical Engineering from Seoul National University in 1983 and 1987, respectively. Since 1986, he has been a member of the faculty of the Department of Electrical Engineering, Ulsan University, where he is currently a Full Professor. His current research interests are the control of electrical machines, power converter circuits, and industrial applications. 